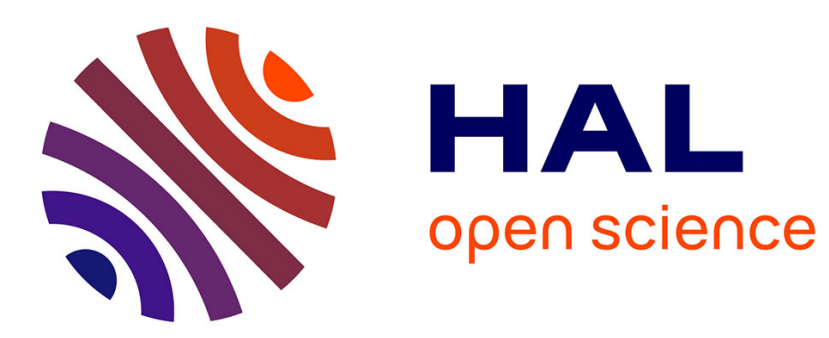

\title{
IVR Wizard of OZ Field Experiment with Less-Literate Telecom Customers
}

Deepak Ranjan Padhi, Rohit Gupta

\section{To cite this version:}

Deepak Ranjan Padhi, Rohit Gupta. IVR Wizard of OZ Field Experiment with Less-Literate Telecom Customers. 16th IFIP Conference on Human-Computer Interaction (INTERACT), Sep 2017, Bombay, India. pp.492-495, 10.1007/978-3-319-68059-0_58 . hal-01679794

\section{HAL Id: hal-01679794 \\ https://hal.inria.fr/hal-01679794}

Submitted on 10 Jan 2018

HAL is a multi-disciplinary open access archive for the deposit and dissemination of scientific research documents, whether they are published or not. The documents may come from teaching and research institutions in France or abroad, or from public or private research centers.
L'archive ouverte pluridisciplinaire HAL, est destinée au dépôt et à la diffusion de documents scientifiques de niveau recherche, publiés ou non, émanant des établissements d'enseignement et de recherche français ou étrangers, des laboratoires publics ou privés.

\section{(c)(1)}

Distributed under a Creative Commons Attribution| 4.0 International License 


\title{
IVR Wizard of OZ Field Experiment with Less-Literate Telecom Customers
}

\author{
Deepak Ranjan Padhi ${ }^{1}$, Rohit Gupta ${ }^{1}$ \\ ${ }^{1}$ Indian Institute of Technology Bombay, Mumbai, India. \\ \{deepak.padhi, rohit7gupta\} @iitb.ac.in
}

\begin{abstract}
Interactive Voice Response (IVR) is a popular and one of the most deployed technology interventions in the developing countries. One of the primary business drivers is that it does not mandate the user to use any technologically advanced device. On the other hand, IVR has been studied for its usability issues. Even for the service providers, IVR costs are higher than services on data channels. However, given the sunk costs and low-technology investments, they are an attractive business proposition and continue to garner support. In this field trip, we propose to have an "experiential" trip of manning and experiencing the system when in use by a less-literate user. Our field trip would allow the participants to "listen" onto and experience first-hand the roller coaster experiential ride when using an IVR system. This will help us to reveal a lot of contextual data such as performance of a low-literate user with IVR, turn taking behaviour, machine and user relationship building, ambiguities etc. This will lead to interventions in the development of dialog structure personification, emotional value association, interaction design and user experience design. The methodology used to conduct the study would be wizard of context, and field observations followed by an affinity analysis.
\end{abstract}

Keywords: IVR $\cdot$ Low Literate $\cdot$ Affinity Diagram $\cdot$ Wizard of Oz

\section{Project Description}

This project is mainly focused on experiencing the different challenges of IVR while interacting with low-literate users. With a virtual set up of a call centre, participants can understand how an IVR works? what are the different issues? What are the opportunities? How to make an IVR better? Through this project a wizard will be built to facilitate interactions between the user and the participant (Behaving as a machine with an IVR script). Our report will include the social aspects of IVR along with the technological aspects. We will highlight the established relationship between a man and a machine. We will also propose the opportunities to support IVRs and making it better in future.

\section{Theoretical Framework}

Interactive Voice Response Systems (IVRs) are used to deliver different services of public interest in developing regions such as banking, healthcare, e-governance, agriculture etc. [1][2][3][4]. IVRs are assumed to be easier systems to deploy and 
sustain. They do not seem to need high-end dedicated resources at the user end but, in fact, can capitalize on fast growing mobile phone networks in the developing regions. In fact, there are more than 7 billion mobile phones around the world as per the report of ICT data and statistics division, May 2015 [5] and $60 \%$ of the subscribers live in developing countries. However, the non-literate and low literate people face great difficulties in using these ICTs having complex information architecture, interactions, navigation and textual interfaces. This brings the question of how to make these ICTs accessible by these users who contribute to more than $15 \%$ population of the world. Researchers have conducted several empirical studies using non-textual UIs, GUIs, IVRs, IVRs with visual augmentations for different types of menu structures, menu positions etc. One of the prime intervention of designing user interfaces targeting these emergent users is IVRs. Interactive voice response (IVR) is a technology that allows a computer to interact with humans through the use of voice. IVRs dialog prompts are usually directed in nature and can engage users with minimal or no training. For example, press 1 for doing an action. However, users in the developing regions are still challenged by the usability issues of such IVRs [6][7][8]. Users report getting frustrated out of their poor interaction with IVRs. The ephemeral nature of audio prompts brings poor 'referability' in users' interaction with the IVRs. Tatchell [9] observes that the services activated using IVRs are difficult to learn, easy to forget and confusing. Users must win over a sequential and hierarchical menu structure using key presses and/or commands to distil the required information. Our main motivation is to find out these challenges within the scope of our experiment and propose solutions for IVR applications.

\section{Method: Wizard of $\mathrm{Oz}$}

We propose a field trip of two days. We intend to setup a virtual call centre which would be manned by volunteers who can speak either of the 3 languages, namely, the local state language (Marathi), the national language (Hindi) and English. Each volunteer would be provided a cell phone and a IVR voice prompt script. We would also print a low-cost A5 sheet pamphlet advertising the availability of free talk time to callers of the published number in a particular time window. We would then circulate this pamphlet amongst the mess workers and house-keeping staff of IIT Bombay. We would also publicize this on WhatsApp messaging platform, as well as directed WhatsApp messages to the target audience. Their participation will be voluntary in nature. They will have to perform a navigation task of mobile recharge using our IVR service.

On the other side, within the Industrial Design Centre, we would setup the Conference Room- 1 as our call centre. There will be 5 volunteers with the cell phones and script. Each volunteer would also be trained on these scrips. During the call, they are required to voice record, using the phone's built-in feature, each IVR interaction. Each phone would also be provided with a split stereo connector so that other field trip participants can also be able to listen to the conversation along with the volunteers. They will also interpret the conversation.

We believe this "listening-in" experiential aspects would be appreciated by the International Researchers, at the emotive and voice modulation level even though the 
language is foreign. After each call, the volunteers would then switch the phone to "Airplane Mode" and explain the conversation to the participants. We would also provide a speaker phone so that the community could live-listen to the experiment.

We hope to highlight the challenges experienced by our users in using the system and connect with those challenges at the personal level using this setup.

The recorded voice conversations would then be subjected to note-taking and the notes created would be analysed using "Affinity Diagrams". The findings from the affinity diagrams would constitute the report.

\section{Outcome/Deliverable}

Presentation and report will constitute the following:

1. Challenges in IVR

2. Experiential aspects of IVR

\section{Team}

Team Size: 10

Group Facilitators (2) - Deepak Ranjan Padhi - PhD scholar at IDC School of Design, IIT Bombay, with focused interest in designing user interfaces with IVRs.

- Rohit Gupta - M.Des student at IDC School of Design, IIT

Bombay, to help in designing the wizard and call centre set up.

We are expecting participation from a diverse group of people who would be interested to work in similar area.

Researchers (2) - Preferably, candidates belonging to an advanced digitalized country, who can contribute for experiment design and analysis.

Field representatives (5) - To help in recruiting users, conducting primary user studies and running a virtual call centre. This position seeks knowledge of Hindi and Marathi and a combination of male and female candidates.

Designers (1) - To help in affinity analysis, creating quick mock-ups of ideas and simulations, sketches and illustrations. 


\section{References}

1. Barnard, E., Plauché, M., \& Davel, M.: The utility of spoken dialog systems. In: Spoken Language Technology Workshop, 2008. SLT 2008. IEEE (pp. 13-16). (2008)

2. Kumar, A., Rajput, N., Chakraborty, D., Agarwal, S. K., \& Nanavati, A. A.: WWTW: the world wide telecom web. In: Proceedings of the 2007 workshop on Networked systems for developing regions (p. 7). ACM (2007)

3. Plauche, M., Nallasamy, U., Pal, J., Wooters, C., \& Ramachandran, D.: Speech recognition for illiterate access to information and technology. In: Information and Communication Technologies and Development, 2006. ICTD'06. International Conference on (pp. 83-92). IEEE. (2006)

4. Shrivastava, A., \& Joshi, A.: Effects of visuals, menu depths, and menu positions on IVR usage by non-tech savvy users. In: Proceedings of the India HCI 2014 Conference on Human Computer Interaction (p. 35). ACM. (2014)

5. ICT Facts and Figures, https://www.itu.int/en/ITUD/Statistics/Documents/facts/ICTFacts Figures2015.pdf.

6. Marics, M. A., \& Engelbeck, G.: Designing voice menu applications for telephones. In: Handbook of human-computer interaction, 1085-1102. (1997)

7. Resnick, P., \& Virzi, R. A: Skip and scan: cleaning up telephone interface. In: Proceedings of the SIGCHI conference on Human factors in computing systems (pp. 419426). ACM. (1992)

8. Yin, M., \& Zhai, S.: Dial and see: tackling the voice menu navigation problem with crossdevice user experience integration. In: Proceedings of the 18th annual ACM symposium on User interface software and technology (pp. 187-190). ACM. (2005)

9. Tatchell, G. R.: Problems with the existing telephony customer interface: The pending eclipse of touch-tone and dial-tone. In: Conference companion on human factors in computing systems (pp. 242-243). ACM. (1996) 